\title{
Lymph node metastases in early gastric cancer, when the East and the West come to terms
}

\author{
Mohamed M. Abdelfatah ${ }^{1}$, Mohamed O. Othman ${ }^{2}$ \\ ${ }^{1}$ Division of Gastroenterology, Department of Internal Medicine, Emory University Hospital, Atlanta, GA, USA; ${ }^{2}$ Gastroenterology and Hepatology \\ Section, Baylor College of Medicine, Houston, TX, USA \\ Correspondence to: Mohamed O. Othman. Chief of Gastroenterology Section, Baylor St Luke's Medical Center, Director of Advanced Endoscopy, \\ Associate Professor of Medline, Baylor College of Medicine, 7200 Cambridge Ave, Houston, TX 77030, USA. Email: mohamed.othman@bcm.edu. \\ Provenance: This is an invited Editorial commissioned by Section Editor Dali Sun (Second Affiliated Hospital of Kunming Medical University, \\ Kunming, China). \\ Comment on: Pessorrusso FCS, Felipe-Silva A, Jacob CE, et al. Risk assessment of lymph node metastases in early gastric adenocarcinoma fulfilling \\ expanded endoscopic resection criteria. Gastrointest Endosc 2018. [Epub ahead of print].
}

Received: 26 September 2018; Accepted: 10 October 2018; Published: 02 November 2018.

doi: $10.21037 / \operatorname{tgh} .2018 .10 .02$

View this article at: http://dx.doi.org/10.21037/tgh.2018.10.02

Endoscopic resection of early gastric cancer (EGC) is limited by the risk of lymph node metastasis (LNM). In general, resection of small (less than $2 \mathrm{~cm}$ ) differentiated EGC which is limited to the mucosa is deemed safe due to negligible risk of lymph node metastasis. Expanding endoscopic resection beyond this criterion has been a matter of debate. In a land mark study by Gotoda et al., the risk of LNM for mucosal differentiated lesions without ulceration, irrespective of size, mucosal differentiated ulcerated lesions $\leq 2 \mathrm{~cm}$, and poorly differentiated lesions $\leq 3 \mathrm{~cm}$ was $0 \%$ (1). Shortly after this landmark study, Gotoda et al. proposed expanding endoscopic resection to include the above mentioned variants of early gastric lesions (Table 1). Multiple studies further confirmed a similar five-year survival rate after endoscopic resection between patients who met expanded criteria versus patients who met the absolute criteria $(2,3)$. As a result, the Japanese Gastric Cancer Association (JGCA) recently published the expanded indications for endoscopic submucosal dissection (ESD) of EGC.

Due to technical improvements in ESD, endoscopists are now able to resect larger and deeper EGCs. However, several roadblocks precluded the deliberate use of ESD for EGC; first, with the exception of Japan, most gastric cancers are diagnosed at late stages due to the absence of gastric cancer screening programs $(4,5)$. Second, it is difficult to determine the depth of invasion of EGC to differentiate mucosal from submucosal lesions $(6,7)$. In addition, LNM at the time of endoscopic resection cannot be reliably excluded using cross-sectional imaging modalities. Likewise, endoscopic ultrasound has had disappointing results in ruling out LNM (8-13). That said, it is impossible to predict the risk of LNM without careful pathological evaluation of the en-block ESD specimens. Typically resected specimen should be sectioned every $2 \mathrm{~mm}$ for an accurate evaluation of LNM. If the ESD was non-curative, further surgical resection would be indicated with added morbidity and mortality.

Over the last decade, there have been limited publications from the West describing the rate of LNM in EGC in the West (14). Pokala et al. investigated the rates of LNM in EGC in the United States. The authors identified 1,577 patients with EGD through the SEER database and found a significantly higher risk of LNM in patients with tumors invading into the submucosa (T1b) tumors compared to mucosal tumors. The risk of LNM in T1b tumor ranged from $8-35 \%$ depending on the tumor size (15). Although these results are in an agreement with what has been published in Eastern Literature, the question of the applicability of expanded criteria in the West remains to be answered.

Recently, Pessorrusso et al. published their experience pertaining to the risk of LNM in EGC in Brazil. The authors evaluated surgically resected EGC specimens for the risk of LNM in a 39-year retrospective cohort. In this cohort, Pessorrusso et al. demonstrated that LNM was seen in three out of $104(2.9 \%)$ patients with EGC fulfilling the criteria for expanded indications versus no 
Table 1 Criteria for endoscopic resection according to the absolute and the expanded indications

Absolute indications
Clinically intramucosal, differentiated type, $\leq 1 \mathrm{~cm}$ in size, UL (-)
Expanded indications
Intramucosal cancer, differentiated type, $>2 \mathrm{~cm}$ in size, UL $(-)$
Intramucosal cancer, differentiated type, $\leq 3 \mathrm{~cm}$ in size, UL (+)
Intramucosal cancer, undifferentiated type, $\leq 2 \mathrm{~cm}$ in size, UL (-)
SM1 cancer ( $<500 \mu$ invasion), differentiated type, $\leq 3 \mathrm{~cm}$ in size

UL, ulcer; +, present; -, absent.

LNM in 34 patients fulfilling the criteria for absolute indication. Interestingly, the three patients with LNM had undifferentiated EGC (16).

The authors' concern regarding the risk of LNM for undifferentiated EGC under the expanded indication is consistent with our recently published meta-analysis in the same topic. In our meta-analysis, the undifferentiated expanded criteria had the highest risk of LNM (25 out of 972 patients " $2.6 \%$ ") (17).

This study by Pessorrusso et al. is an additional evidence that LNM in EGC could be similar in Eastern and Western populations. This may encourage western endoscopists to expand the frontier of endoscopic resection to include those patients. Caution has to be had since the rate of en bloc and $\mathrm{R} 0$ resection is lower in patients with expanded criteria given the possibility of fibrosis and lack of clear margins in some categories of the expanded criteria. In addition, not all criteria for expanded indications had similar results. It appears that undifferentiated lesions or lesions with submucosal invasions are more worrisome for LNM compared with other expanded indications criteria $(18,19)$.

The study by Pessorrusso et al. has its limitations. As the authors have highlighted, the retrospective nature and the possibility of selection/referral bias can limit the generalizability of the study. The study extended over four decades, which made the study vulnerable to lead time bias; bias from different surgical resection techniques and bias from different methods of tissue handling during pathological assessment.

I would like to congratulate the author on their efforts. Indeed, any western experience is needed to add a piece of evidence to our scant literature originating from the West. Whether racial, environmental or genetic factors can affect tumor behaviors and risk of LNM remains to be answered by future publications.

\section{Acknowledgements}

None.

\section{Footnote}

Conflicts of Interest: MO Othman: Consultant for Olympus and Boston Scientific corporation. MM Abdelfatah has no conflicts of interest to declare.

\section{References}

1. Gotoda T, Yanagisawa A, Sasako M, et al. Incidence of lymph node metastasis from early gastric cancer: estimation with a large number of cases at two large centers. Gastric Cancer 2000;3:219-25.

2. Gotoda T, Iwasaki M, Kusano C, et al. Endoscopic resection of early gastric cancer treated by guideline and expanded National Cancer Centre criteria. Br J Surg 2010;97:868-71.

3. Isomoto H, Shikuwa S, Yamaguchi N, et al. Endoscopic submucosal dissection for early gastric cancer: a large-scale feasibility study. Gut 2009;58:331-6.

4. Imaoka W, Ida K, Katoh T, et al. Is curative endoscopic treatment of early gastric cancer possible? Endoscopy 1987;19 Suppl 1:7-11.

5. Green PH, O'Toole KM, Slonim D, et al. Increasing incidence and excellent survival of patients with early gastric cancer: experience in a United States medical center. Am J Med 1988;85:658-61.

6. Sano T, Okuyama Y, Kobori O, et al. Early gastric cancer. Endoscopic diagnosis of depth of invasion. Dig Dis Sci 1990;35:1340-4.

7. Ohashi S, Segawa K, Okamura S, et al. The utility of endoscopic ultrasonography and endoscopy in the endoscopic mucosal resection of early gastric cancer. Gut 1999;45:599-604.

8. Mocellin S, Pasquali S. Diagnostic accuracy of endoscopic ultrasonography (EUS) for the preoperative locoregional staging of primary gastric cancer. Cochrane Database Syst Rev 2015;(2):CD009944.

9. Sugano K, Sato K, Yao K. New diagnostic approaches for early detection of gastric cancer. Dig Dis 2004:22:327-33.

10. Tajiri H, Ohtsu A, Boku N, et al. Routine endoscopy using electronic endoscopes for gastric cancer diagnosis: retrospective study of inconsistencies between endoscopic 
and biopsy diagnoses. Cancer Detect Prev 2001;25:166-73.

11. Kawahara Y, Takenaka R, Okada H, et al. Novel chromoendoscopic method using an acetic acidindigocarmine mixture for diagnostic accuracy in delineating the margin of early gastric cancers. Dig Endosc 2009;21:14-9.

12. Ezoe Y, Muto M, Uedo N, et al. Magnifying narrowband imaging is more accurate than conventional whitelight imaging in diagnosis of gastric mucosal cancer. Gastroenterology 2011;141:2017-2025.e3.

13. Yada T, Yokoi C, Uemura N. The current state of diagnosis and treatment for early gastric cancer. Diagn Ther Endosc 2013;2013:241320.

14. Probst A, Schneider A, Schaller T, et al. Endoscopic submucosal dissection for early gastric cancer: are expanded resection criteria safe for Western patients? Endoscopy 2017;49:855-65.

15. Pokala SK, Zhang C, Chen Z, et al. Lymph node metastasis in early gastric adenocarcinoma in the United States of America. Endoscopy 2018;50:479-86.

doi: $10.21037 / \operatorname{tgh} .2018 .10 .02$

Cite this article as: Abdelfatah MM, Othman MO. Lymph node metastases in early gastric cancer, when the East and the West come to terms. Transl Gastroenterol Hepatol 2018;3:87.
16. Pessorrusso FCS, Felipe-Silva A, Jacob CE, et al. Risk assessment of lymph node metastases in early gastric adenocarcinoma fulfilling expanded endoscopic resection criteria. Gastrointest Endosc 2018. [Epub ahead of print].

17. Abdelfatah MM, Barakat M, Lee H, et al. The incidence of lymph node metastasis in early gastric cancer according to the expanded criteria in comparison with the absolute criteria of the Japanese Gastric Cancer Association: a systematic review of the literature and meta-analysis. Gastrointest Endosc 2018;87:338-47.

18. Abdelfatah MM, Barakat $M$, Lee $H$, et al. The incidence of lymph node metastasis in early gastric cancer according to the expanded criteria in comparison with the absolute criteria of the Japanese Gastric Cancer Association: a systematic review of the literature and meta-analysis. Gastrointest Endosc 2018;87:338-47.

19. Abdelfatah MM, Barakat M, Othman MO, et al. The incidence of lymph node metastasis in submucosal early gastric cancer according to the expanded criteria: a systematic review. Surg Endosc 2018. [Epub ahead of print]. 